\title{
PENGETAHUAN PERAWAT TENTANG PENERAPAN PELAKSANAAN PENCEGAHAN INSIDEN PADA PASIEN RESIKO JATUH
}

\author{
Ayu Maulina ${ }^{1}$, Nelly Febriani² \\ ${ }^{1}$ Program Studi Ilmu Keperawatan, Fakultas Ilmu-Ilmu Kesehatan, Universitas Pembangunan Nasional \\ "Veteran, Jl. Limo Raya Depok 16515 \\ ${ }^{2}$ Departemen Managemen Keperawatan, Fakultas Ilmu-Ilmu Kesehatan, Universitas Pembangunan Nasional \\ "Veteran, Jl. Limo Raya Depok 16515 \\ Email : aiiumaulina@gmail.com
}

\begin{abstract}
Abstrak
Salah satu dari enam sasaran keselamatan pasien adalah pencegahan pasien jatuh. Pelaksanaan pencegahan insiden pada pasien resiko jatuh sangat berhubungan erat dengan pengetahuan dan keterampilan perawat. Penelitian ini bertujuan menganalisis hubungan tingkat pengetahuan perawat dengan penerapan pelaksanaan pencegahan insiden pada pasien resiko jatuh. Penelitian ini menggunakan metode Deskriptif Kuantitatif dengan pendekatan cross sectional pada 52 perawat pelaksana, hasil analisis bivariat dengan uji chi square menunjukkan bahwa ada hubungan yang signifikan antara pengetahuan dengan penerapan pelaksanaan pencegahan pasien resiko jatuh $(\mathrm{P}=$ 0,001). Kejadian jatuh merupakan kejadian yang dapat dicegah, karena itu sebagai ujung tombak dalam pelayanan kesehatan sangat penting bagi perawat untuk meningkatkan pengetahuan, keterampilan, dan mematuhi pelaksanaan pencegahan pasien jatuh sesuai dengan prosedur yang sudah ada. Faktor yang paling berpengaruh pada pencegahan pasien jatuh adalah standar operasional prosedur sebagai acuan yang tepat untuk menerapkan keselamatan pasien dengan baik.
\end{abstract}

Kata kunci : Pelaksanaan Pencegahan Pasien Resiko Jatuh, Pengetahuan.

\begin{abstract}
One of the six patient safety goals is the prevention of patient falls. Implementation of incident prevention in patients risk of falling is very closely linked with the knowledge and skills of nurses. The purpose of this study was to find out the correlation between nurses' knowledge with the application execution incident prevention in patients at risk of falling RSPC. This study used a descriptive quantitative methods with cross sectional approach. The population in this study is 52 nurses at mawar and aster room. The results of bivariate analyzes with chi square test showed that there was a significant relationship between knowledge of the application execution
\end{abstract}


prevention fall risk patients $(\mathrm{p}=0.001$ means $\mathrm{p}<0.05)$. Incidence of falls are preventable events, because it as the spearhead in health care is very important for nurses to enhance their knowledge, skills, and adhere to the implementation of patient falls prevention in accordance with existing procedures. The most influential factor in the prevention of patient falls is the standard operating procedures as appropriate references to well implement patient safety.

Key words : Implementation of Risk Patient Fall Prevention, Knowledge 


\section{Pendahuluan}

Keselamatan pasien sangat penting diterapkan rumah sakit, karena kalau tidak diterapkan akan berdampak pada penurunan kepercayaan masyarakat terhadap pelayanan kesehatan yang ada dan berakibat pada penurunan mutu pelayanan rumah sakit. Pelayanan yang bermutu dan aman bagi pasien saling berkaitan dan tidak dapat dipisah - pisahkan (Cahyono, 2008). Six Goal Pasient safety (Enam Sasaran Keselamatan pasien) merupakan beberapa syarat yang harus diterapkan rumah sakit untuk keselamatan pasien, meliputi : ketepatan identifikasi pasien, peningkatan keamanan obat yang perlu diwaspadai, peningkatan komunikasi yang efektif, kepastian tepat lokasi- tepat prosedur- tepat pasien post operasi, pengurangan resiko infeksi dan pengurangan/ pencegahan pasien resiko jatuh. Jatuh merupakan kejadian yang dapat dicegah, perawat perlu melakukan pedoman prevention falls yaitu dengan monitoring ketat pasien risiko tinggi (kunjungi dan monitor pasien/ 1jam, tempatkan pasien di kamar yang paling dekat dengan nurse station jika memungkinkan), melibatkan pasien/ keluarga dalam pencegahan jatuh (KKPRS, 2008). Kejadian pasien jatuh perlu ditanggulangi sehingga KTD menjadi $0 \%$, namun masih ada KTD lebih dari angka tersebut. Hal ini dipublikasi oleh WHO pada 2007 menemukan KTD dengan rentang 3,2$16,6 \%$ pada rumah sakit diberbagai negara, yaitu Amerika, Inggris, Denmark dan Australia (Depkes RI, 2008). Morse melaporkan 2,2-7\% kejadian pasien jatuh/ 1000 tempat tidur per hari diruang perawatan akut per tahun, $29-48 \%$ pasien mengalami luka, dan 7,5\% dengan luka-luka serius (Nadzam, 2009).

Data diatas secara jelas menunjukkan bahwa telah terjadi KTD di berbagai jenis rumah sakit di Dunia dan perlu dilakukan penatalaksanaan prosedur pencegahan pasien jatuh. Pelaporan data di Indonesia tentang KTD dan KNC belum banyak dilakukan oleh rumah sakit di Indonesia. Komite Keselamatan Pasien Rumah Sakit (KKPRS) melaporkan, mulai September 2006-2011 terjadi insiden : KTD sebanyak 249 kasus dan KNC 283 kasus. Hal ini terjadi disebabkan rumah sakit masih kurang peduli 
melaporkan tentang pelaksanaan keselamatan pasien.

\section{Metode Penelitian}

Penelitian ini menggunakan metode deskriptif kuantitatif dengan desain penelitian "cross sectional" Peneliti menggunakan total sampling dengan jumlah 52 perawat pelaksana di Rumah Sakit Puri Cinere.

\section{Hasil Penelitian}

Tabel 1. Gambaran Karakteristik

Perawat Pelaksana di Ruang "Mawar dan Aster" Rumah Sakit Puri Cinere, Depok

Tahun 2014

Hasil penelitian ini terdiri dari 52 perawat pelaksana di RSPC yang menjadi responden penelitian dan sebagian besar berusia $<30$ tahun $(55,8 \%)$, perempuan $(86,5 \%)$, lulusan pendidikan D3 Keperawatan (75\%), dan memiliki masa kerja $<5$ tahun $(51,9 \%)$.

Tabel 5.2 Gambaran Pengetahuan Perawat Pelaksana di Ruang "Mawar dan Aster" Rumah Sakit Puri Cinere, Depok Tahun 2014

\begin{tabular}{lll}
\hline Pengetahuan & Frekuensi & $\begin{array}{c}\text { Persentase } \\
\text { (\%) }\end{array}$ \\
\hline Rendah & 14 & 26,9 \\
Tinggi & 38 & 73,1 \\
\hline
\end{tabular}

\begin{tabular}{|c|c|c|c|}
\hline $\begin{array}{l}\mathbf{N} \\
\mathbf{0}\end{array}$ & $\begin{array}{l}\text { Karakteristi } \\
\text { k Perawat }\end{array}$ & $\begin{array}{l}\text { Pelaksan } \\
\text { a }\end{array}$ & $\begin{array}{l}\text { Frekuensi } \\
\text { Persentas } \\
\text { e (\%) }\end{array}$ \\
\hline \multirow[t]{3}{*}{1.} & Usia & & \\
\hline & $<30$ Tahun & 29 & 55,8 \\
\hline & $\geq 30$ Tahun & 23 & 44,2 \\
\hline \multirow[t]{4}{*}{2.} & Jenis & & \\
\hline & Kelamin & 7 & 13,5 \\
\hline & Laki-laki & 45 & 86,5 \\
\hline & Perempuan & & \\
\hline \multirow[t]{6}{*}{3.} & Tingkat & & \\
\hline & Pendidikan & & \\
\hline & D3 & & \\
\hline & $\begin{array}{l}\text { Keperawata } \\
\text { n }\end{array}$ & 39 & 75,0 \\
\hline & $\mathrm{S} 1$ & 13 & 25,0 \\
\hline & Keperawata & & \\
\hline \multirow[t]{6}{*}{4.} & $\mathrm{n}$ & & \\
\hline & & 27 & 51,9 \\
\hline & Masa Kerja & 25 & 48,1 \\
\hline & $<5$ Tahun & & \\
\hline & $\geq 5$ Tahun & & \\
\hline & Total & & 100 \\
\hline
\end{tabular}

Berdasarkan tabel 2, dari 52 responden yang diteliti dapat dilihat bahwa 14 responden $(26,9 \%)$ memiliki pengetahuan pada kategori rendah sedangkan pada kategori tinggi 38 responden $(73,1 \%)$.

Tabel 3 Gambaran Penerapan Pelaksanaan Pencegahan Pasien Resiko Jatuh di Ruang "Mawar dan Aster" Rumah Sakit Puri Cinere, Depok 2014 


\begin{tabular}{lcc}
\hline Penerapan & Frekuensi & $\begin{array}{c}\text { Persentase } \\
\mathbf{( \% )}\end{array}$ \\
\hline Tidak & 37 & 71,2 \\
Diterapkan & & \\
Diterapkan & 15 & 28,8 \\
& & \\
\multicolumn{1}{c}{ Total } & 52 & 100 \\
\hline
\end{tabular}

Berdasarkan tabel 3, 15 responden $(28,8 \%)$ menerapkan pencegahan insiden pada pasien risiko jatuh sedangkan sebanyak 37 responden $(71,2 \%)$ penerapan pelaksanaan pencegahan insiden pada pasien risiko jatuh tidak diterapkan.

Tabel 4. Hubungan Karakteristik Perawat Pelaksana dengan Penerapan Pelaksanaan Pencegahan Insiden pada Pasien resiko Jatuh di Ruang "Mawar dan Aster" Rumah Sakit
Puri Cinere, Depok Tahun 2014

\begin{tabular}{cccc}
\hline Karakteristik & Penerapan & \\
Perawat & Pelaksanaan & & \\
Pelaksana & $\begin{array}{c}\text { Pencegahan Resiko } \\
\text { Jatuh Total }\end{array}$ & p & Odd Ratio \\
& & & \\
& Value & \\
& Tidak & Diterapk & \\
& Diterapk & an & \\
& & \\
\end{tabular}

$\begin{array}{lcc}\geq 30 \text { Tahun } & 11 & 12 \\ (47,8 \%) & (52,2 \%)\end{array}$

Jenis

$\begin{array}{lllll}\text { Kelamin } & & & 0,369 & 0,658 \\ & 1(14,3 \% & 6 & & (0,041- \\ \text { Laki-laki } & ) & (85,7 \%) & 3,361) \\ \text { Perempuan } & 14 & 31 & \\ & (31,1 \%) & (68,9 \%) & \end{array}$

Tingkat

Pendidikan

$\begin{array}{lllll}\text { D3 } & 9 & 30 & 0,159 & 2,857 \\ \text { Keperawatan } & (23,1 \%) & (76,9 \%) & & (0,763- \\ & & & 10,702)\end{array}$

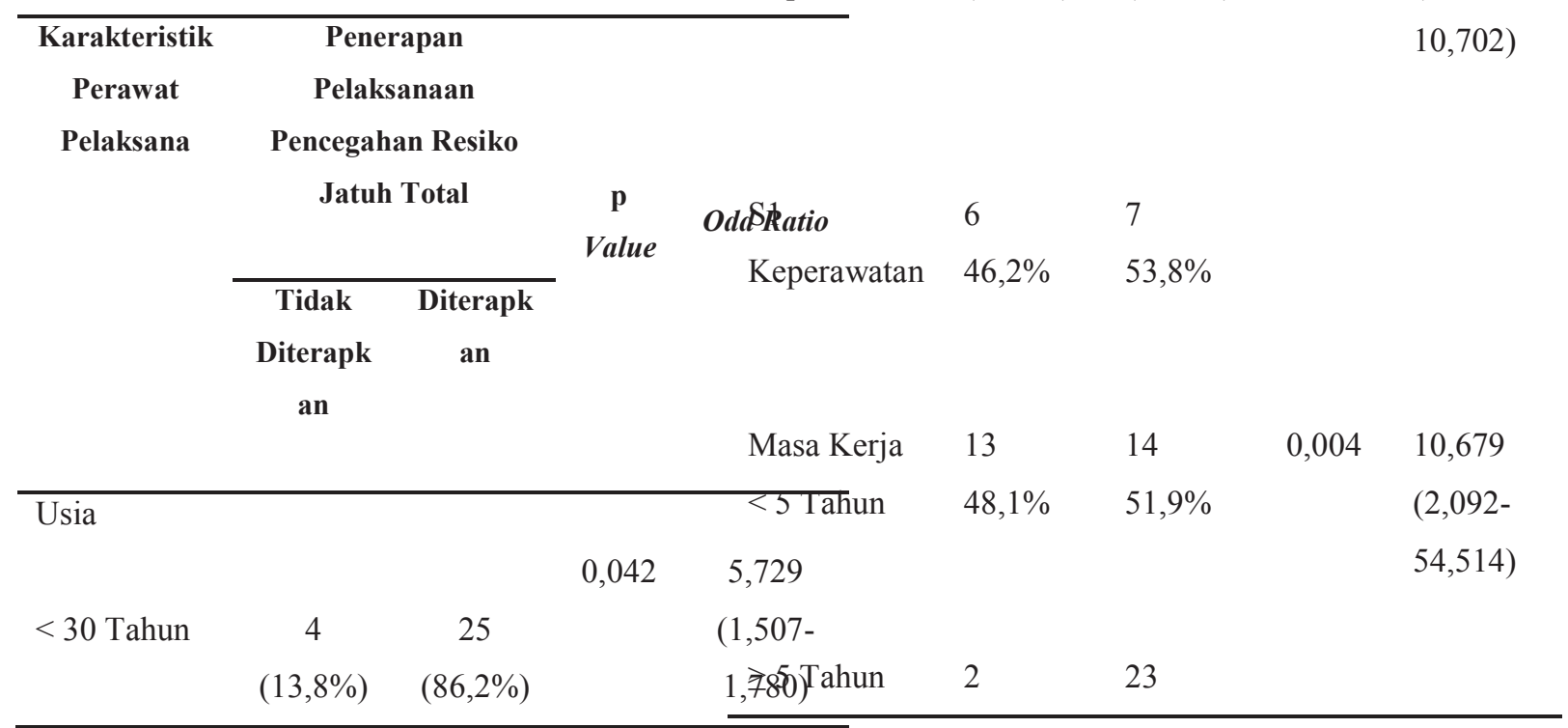




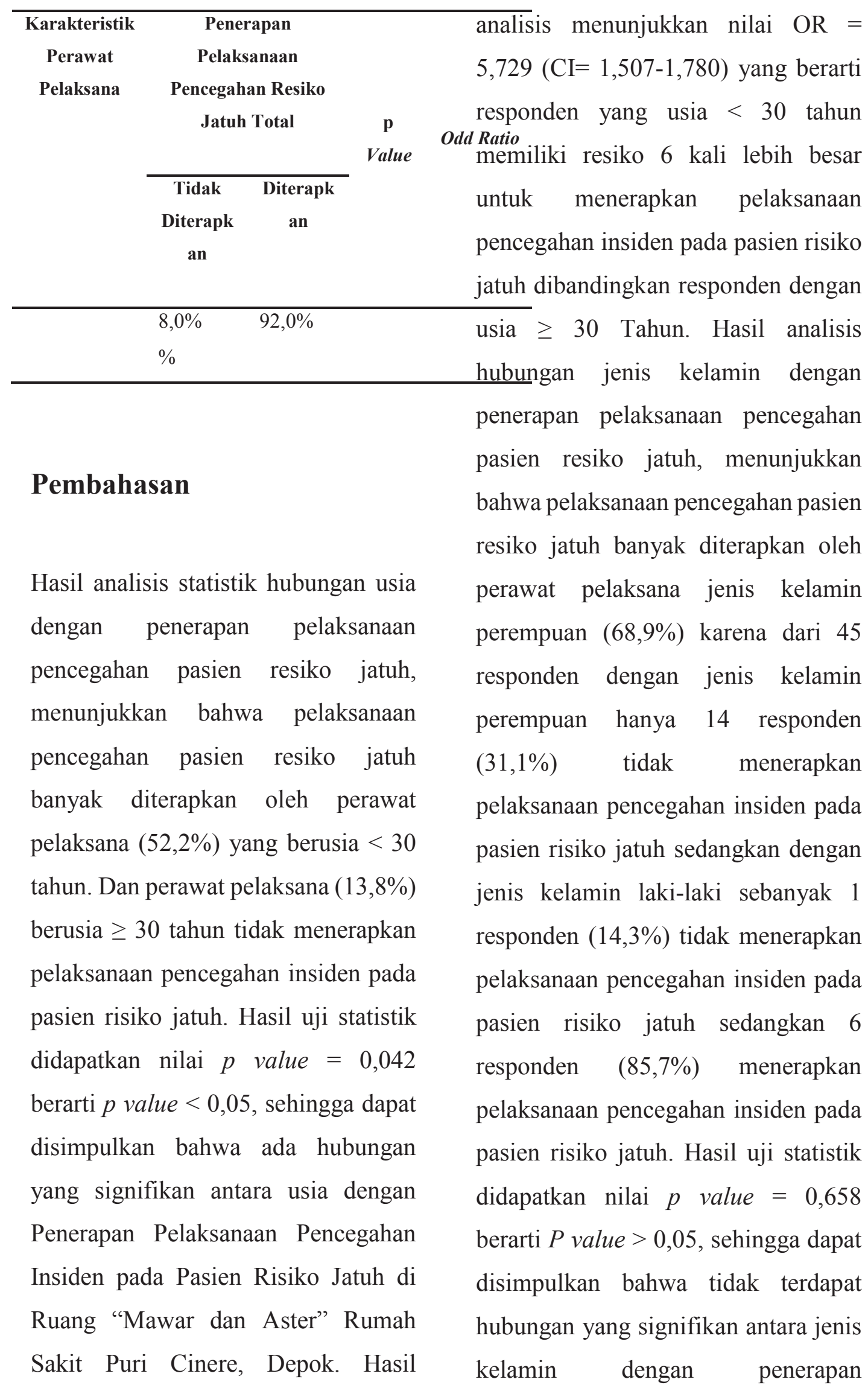


pelaksanaanpencegahan insiden pada pasien risiko jatuh remaja di Ruang "Mawar dan Aster" Rumah Sakit Puri Cinere, Depok. Berdasarkan tabel silang (cross tabulation) diatas dari 39 responden dengan pendidikan D3 Keperawatan dapat dilihat bahwa sebanyak 9 responden $(23,1 \%)$ tidak menerapkan pelaksanaan pencegahan insiden pada pasien risiko jatuh sedangkan 30 responden $(76,9 \%)$ menerapkan pelaksanaan pencegahan insiden pada pasien risiko jatuh. Dari 13 responden dengan pendidikan S1 Keperawatan dapat dilihat bahwa sebanyak 6 responden $(46,2 \%)$ tidak menerapkan pelaksanaan pencegahan insiden pada pasien risiko jatuh sedangkan 7 responden $\quad(53,8 \%)$ menerapkan pelaksanaan pencegahan insiden pada pasien risiko jatuh. Hasil uji statistik didapatkan nilai $P$ value $=$ 0,159 berarti $p$ value $>0,05$, sehingga dapat disimpulkan bahwa tidak terdapat hubungan yang signifikan antara pendidikan dengan

Penerapan Pelaksanaan Pencegahan Insiden pada Pasien Risiko Jatuh remaja di Ruang "Mawar dan Aster" Rumah Sakit Puri Cinere, Depok. Berdasarkan tabel silang (cross tabulation) diatas dari 13 responden dengan masa kerja $<5$ tahun dapat dilihat bahwa sebanyak 13 responden (48,1\%) tidak menerapkan pelaksanaan pencegahan insiden pada pasien risiko jatuh sedangkan 14 responden $(51,9 \%)$ menerapkan pelaksanaan pencegahan insiden pada pasien risiko jatuh. Dari 25 responden dengan masa kerja $\geq 5$ tahun dapat dilihat bahwa sebanyak 2 responden (8\%) tidak menerapkan pelaksanaan pencegahan insiden pada pasien risiko jatuh sedangkan 23 responden (92\%) menerapkan pelaksanaan pencegahan insiden pada pasien risiko jatuh.

Hasil uji statistik didapatkan nilai $P$ value $=0,004$ berarti $P$ value $<0,05$, sehingga dapat disimpulkan bahwa ada hubungan yang signifikan antara masa kerja dengan penerapan pelaksanaan pencegahan insiden pada pasien risiko jatuh remaja di Ruang "Mawar dan Aster" Rumah Sakit Puri Cinere, Depok. Hasil analisis menunjukkan nilai $\mathrm{OR}=10,679(\mathrm{CI}=$ 2,092 - 54,514) yang berarti responden yang masa kerja $\geq 5$ tahun memiliki resiko 11 kali lebih besar untuk menerapkan pelaksanaan pencegahan insiden pada pasien risiko jatuh 
dibandingkan responden dengan masa kerja $<5$ tahun.

\section{Kesimpulan}

Karakteristik perawat pelaksana di Rumah Sakit Puri Cinere yang menjadi responden penelitian sebagian besar berusia $<30$ tahun, berjenis kelamin perempuan, lulusan pendidikan D3 Keperawatan, dan memiliki masa kerja $<5$ tahun. Hasil penelitian pengetahuan perawat Rumah Sakit Puri Cinere adalah 26,9\% memiliki pengetahuan pada kategori rendah sedangkan sebanyak $73,1 \%$ memiliki pengetahuan pada kategori tinggi. Hasil penelitian penerapan pelaksanaan pencegahan insiden pada pasien resiko jatuh ditemukan 71,2\% tidak menerapkan pelaksanaan pencegahan insiden pada pasien resiko jatuh sedangkan $28,8 \%$ menerapkan pelaksanaan pencegahan insiden pada pasien resiko jatuh. Adanya hubungan yang signifikan antara usia, masa kerja dan pengetahuan perawat pelaksana dengan penerapan pelaksanaan pencegahan insiden pada pasien resiko jatuh. Tidak ditemukan adanya hubungan yang signifikan antara jenis kelamin dan pendidikan dengan penerapan pelaksanaan pencegahan insiden pada pasien resiko jatuh.

\section{Daftar Pustaka}

Cahyono. (2008). Membangun budaya keselamatan pasien dalam praktek kedokteran. Yogyakarta : Kanisius.

Depkes RI. (2008). Panduan nasional keselamatan pasien rumah sakit: Utamakan keselamatan pasien. Edisi 2. Jakarta : Depkes RI.

Komite Keselamatan Pasien Rumah Sakit (KKPRS). (2008). Pedoman Pelaporan Insiden Keselamatan Pasien (IKP). Jakarta : KKPRS.

Komite Keselamatan Pasien Rumah Sakit (KKPRS). (2012). Laporan insiden keselamatan pasien (IKP). Jakarta : KKPRS

Nazam, D.M. (2009). Nurses' role in communication and patient saafety. Journal of Nursing Care Quality. Vol 24. No 3 pp 184-188. Di akses 9 november 2013.

Notoatmodjo, S. (2010). Metodologi Penelitian Kesehatan. Jakarta : PT. Rineka Cipta. 